\title{
Developing a socially transformative focus in Occupational Therapy: insights from South African practice
}

\author{
Leigh-Ann Richards, Bsc (OT) UCT \\ Clinical Educator, Division of Occupational Therapy, Department of Health and Rehabilitation Sciences, University of Cape Town
}

Roshan Galvaan, BSc (OT) UCT, MSc (OT) UCT, PhD (OT) UCT

Professor, Division of Occupational Therapy, Department of Health and Rehabilitation Sciences, University of Cape Town

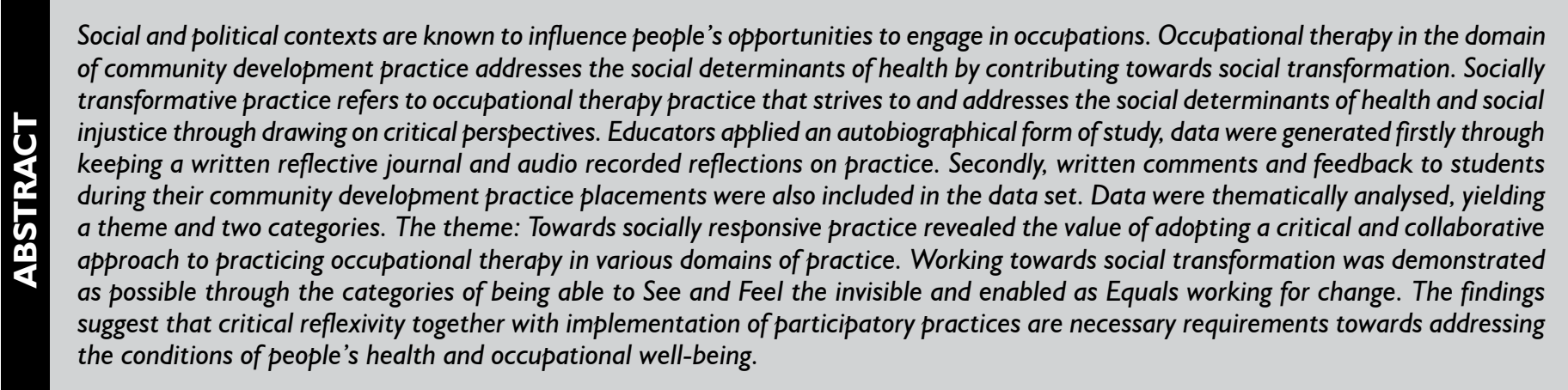

Key words: Occupational therapy practice; social transformation; participatory practice; Occupation-based community development

\section{INTRODUCTION}

Addressing the social determinants of health is a national priority in South Africa given the current profile of the burden of infectious and non-communicable diseases, together with the prevailing social inequalities and inadequate health resourcing nationally'. Social determinants of health refers to general socioeconomic, cultural, environmental, working conditions, social and community as well as individual lifestyle factors that affect health outcomes for various populations ${ }^{2}$. The Department of Health has acknowledged that health professionals in the public sector have to respond to these challenges by promoting health ${ }^{3}$. Mayosi and Benatar note that the public health sector "remains the sole provider of healthcare for more than $\mathbf{4 0}$ million people who are uninsured and who constitute $84 \%$ of the national population"1:1344. The current ratio of occupational therapists in relation to potential service users in South Africa is I: I $000^{1 *}$.

The Department of Health is the main employer of occupational therapists in South Africa, with the 1570 public health sector occupational therapists providing services to a population of over 50 million $^{4}$. The distribution and under-resourcing of occupational therapists influence the impact of services. In this way, resourcing for occupational therapy and the focus of occupational therapy services are not optimally suited to address the social determinants of health. The majority of service users who access public services are uninsured and live in communities where access to basic services such as water, electricity and housing is limited and poverty is rife. These conditions persist as one of the

I*Calculated as follows: 4782 registered OT (HPCSA stats, May 2016) divided by total population 54.9 million. consequences of a legacy of apartheid ${ }^{5}$. The under-resourced public health sector in terms of the appointment of therapists suggests that having a predominant individualistic approach to conceptualise occupational engagement and deliver services may not allow the occupational therapy profession to meet the health needs of the majority of South Africans. Hammel and Iwama ${ }^{6}$ advocate that the profession should recognise the way in which social, structural and political contexts of people's lives are known to affect both individuals' abilities to engage in occupations as well as shape how communities participate. This requires that occupational therapists adopt a focus of social transformation in considering and addressing the socio-political factors that affect people's ability to engage in occupations.

\section{Community Development Practice: a domain addressing the social determinants of health}

The Occupation-based Community Development (ObCD) framework was developed at the University of Cape Town in South Africa ${ }^{7}$ to guide practice which aims to address the factors influencing occupational engagement. The ObCD framework draws on interdisciplinary theories and occupational science constructs to guide a process-orientated approach to practice ${ }^{7}$. The framework interprets and applies occupational science concepts and constructs and prioritises the formation of partnerships with marginalised groups in order to respond to occupational injustices and promote social change. The partnerships involve establishing and building authentic relationships with marginalised individuals and groups of people, while gaining mutual understanding of their occupational engagement and needs. In doing so, the framework guides practice that advances occupational rights and wellbeing ${ }^{8}$. The study that this paper reports on asked: What insights could 
be learned from the way that occupational therapy addresses the social determinants of health through the lens of Occupation-based Community Development practice?

\section{Community Development Practice in occupational therapy at the University of Cape Town}

Each final year, undergraduate occupational therapy student at the University of Cape Town completes a community development practice learning placement over a 7 week period. Placements occur at various sites with the sites remaining consistent over the years. The students apply the ObCD Framework to guide and develop their practice during these placements and are expected to develop a campaign ${ }^{7}$. This campaign is an intervention designed in collaboration with members of the community and plans how to collaboratively address a mutually identified concern in a particular community. Students completing practice learning placements in the domain of community development practice are required to complete planning, evaluation and learner's written reports, commonly referred to as logs. The former logs describe plans for and evaluations of the students' practice while learners' logs are short reflective journals that capture students' learning. Each student is assigned a Clinical Educator who provides support and guidance in the development of the campaigns on site. This occurs through face-to-face supervision consultations and providing feedback on the students' logs in order to ensure that students are able to integrate theory into practice.

\section{Methods}

Autobiographical self-study is a research method which aims to display a pattern of experience ${ }^{9}$ and was applied in the study reported on in this paper. Informed by various narrative forms, this method aims to enrich understandings of known concepts and experiences. Autobiographical narrative especially promotes self- development and a better understanding of one's practice ${ }^{10}$.

For this study, I (the first author) created a reflective journal in which I critically considered my experiences of supervision and practicing occupational therapy in South Africa in relation to the research question. In so doing, I reflected on practice obtained in diverse practice settings, namely:

I. Community Service (2006) in Ngqeleni (Eastern Cape)

2. A public health rehabilitation centre (3 years)

3. A community development practice in a non-profit organisation for persons with disabilities (6 years)

4. As a Clinical Educator supervising students practicing Community Development Practice specifically since 2012.

These reflections were captured in a journal over a period of 3 months and served as the primary set of data.

As a second source of data, I reviewed my comments to occupational therapy students in practice learning over a period of two years. Sections of the written work containing my comments to students were extracted and placed in a separate document as the second source of data in this study. None of the students' reflections were used as data but my comments on their reflections needed to be reviewed alongside students' reflections. Further reflection on these comments and my reflective journal were collated and analysed. The two sets of data were then analysed by both authors.

Applying a thematic analysis to the above data sets, the authors identified codes (similar units or concepts) that regularly arose in the data and then grouped codes into categories. I listened to my voice recordings of further interpretations in order to discuss this in the deeper analysis of the data with the co-author. This allowed for a rich interpretation and understanding of the experiences and more detailed contextual insights into each category. The authors then further discussed the categories and integrated their interpretations of the data. The various interpretations of the data were explored through individual and collective analysis and discussion by the authors ". This exploration occurred through extended discus- sions about the analysis between the co-authors so that multiple interpretations were identified as possible categories of the findings.

With regards to transferability of the study findings, a description of the context in which the data were generated was described and new insights offered may be considered in terms of applicability to similar situations. Credibility was ensured by clearly describing the method of data collection and representation. Since I generated the data, not using the students' writing, ensured that students' privacy and confidentiality were maintained. Given the nature of this data, ethical clearance was not required. My reflections are personal and reflect an honest account of my experiences and that which I had witnessed in supervising students and practicing in South Africa. Beneficence was upheld throughout the research process by not naming or making reference to students' identities, practice learning sites and communities in which they worked and lived.

\section{Findings}

One theme, that is, Towards Socially Responsive Practice and two categories, namely Seeing and feeling the invisible and Equals working for change emerged from the data. The following section describes the categories and then the theme.

\section{Category I: Seeing and Feeling the Invisible}

The social determinants of health and burden of non-communicable disease became more apparent to the first author when practicing in communities where social inequality and poverty prevailed. In the excerpt below the first author expressed the tension experienced in balancing the patients' health needs versus their social needs.

My patients didn't need a shoulder-elbow sling (which I had to sew myself); they didn't need a splint or even a wheelchair. They needed to live a dignified life.

In my role as a therapist, I, reflected on how I questioned the effect of my clinical solutions to address the health needs of my patients. I noticed this amidst a context of overwhelming chronic poverty and injustice. I described the daily struggles that people would navigate to access my occupational therapy services in a rural village.

I had patients being pushed in wheelbarrows for almost $5+\mathrm{km}$ desperately wanting to see the "Doctor of Disability" (Ugqirha Kubazekileyo) as word had quickly spread that she was doing assessments (with no equipment just pen and paper) advising the Medical Officers whether or not to approve a disability grant. Poverty was everywhere and there were many times that I would just recommend the grant because this human being in front of me hadn't eaten a decent meal in so long. I just approved it.

I questioned the value of a service that only addressed individual aspects of a person's performance, such as physical or psychosocial factors, and then for the person to be discharged back into a life of extreme poverty. The extract below illustrates the doubt and selfcriticism experienced when confronting this limitation of practice.

So there I was, every day visiting clinics with queues of people waiting for me, delivering wheelchairs to huts that were located on a 90 degree hill which the driver and I had to hoist the wheelchair up with rope with the help of family members. I knew that this chair and the person were never going to come down this hill. The person I fitted the seat for was skin and bones. The family was so grateful; they gave me a fresh piece of meat wrapped in newspaper with flies sitting on it. I smiled. But thought again: "What on earth am I doing here?"

I was critical of my practice and saw that I needed to find ways of addressing its limitations. I noticed a similar occurrence for students during their community development practice, where they also critically reflected on their practice and its impact in the lives of the people that they worked with. Students lamented the negligible difference that they thought they were making in light of harsh conditions, such as no access to transport and a pervasive hopelessness sometimes faced by students and clients. The reflections on the students' work showed that these lamentations 
could be viewed as progress towards acknowledging the relationship between the social determinants of health and occupational therapy in practice. I, in my role as clinical educator, commented in my written feedback to the students that

Acknowledging the harshness and injustice of the context is a start and you have done well to make the decision to rise up to the challenge rather than to avoid and experience the overwhelming helplessness inherent in this work.

Yes, questioning or doubting whether what you are doing is going to make a huge difference, or not, is normal. You have to remember we are ALL contributing, not just OTs, but many other stakeholders as well. Every contribution is valuable and builds on the other.

Students reflected in their learner logs how they simply couldn't continue ignoring the life that people have to live and how it has come to be accepted. I commented to students:

When you say it is hard to ignore the life that people live and how uncomfortable it makes you; its ok to acknowledge that discomfort and emotion.

Students' affective responses and sense of equity and justice were often challenged while engaging with clients in their contexts. Students shared that they were aware of injustice as a concept, yet experiencing the frustrations and feelings of oppression with their clients gave them a different perspective. In response I commented that:

Experiencing injustice and inequality for yourself is definitely sobering.

The data revealed that practicing in this context affected students emotionally, leaving them emotionally strained. While waiting at the day hospital with a suicidal client, a student witnessed the constraints of the prolonged waiting periods in the public health system. Following the supervision session, I reflected on my response to the student:

She [the student] was in tears as she shared about the blood on the floor and people bleeding and a woman almost miscarrying in the waiting area. All I could think of was: Why the heck did you not do this or that? I felt ashamed. I comforted her (which was hard for me to do) and then gently reminded her of the health system channels that the organisation needs to follow next time.

The above response illustrates a missed opportunity to engage in a reflective conversation with the student afterwards about the inequities in health services and what it means to practice in relation to this. The helplessness that students and I expressed in relation to the limited resources for health services was overwhelming. It potentially affected their motivation to practice and influenced the students and my perception of our role and relationship with clients. However, recognising the emotional responses as humane in the face of injustices, students and I accessed a sense of agency where we recognised ourselves as a necessary human resource vital to contributing to change. My comments showed that dealing with the emotional strain was part of being authentic in practice.

Acknowledging your emotions and being critical of oneself is essential in order to open yourself to engage with what is happening out there

I noted that students' perceptions of how they viewed themselves as professionals changed during their practice learning placements. Many students shifted to viewing their clients as fellow citizens and not only as clients. I provided students with the following feedback in response:

Being both a citizen and therapist is needed in this country as seeing yourself as a citizen brings a different lens to understanding your role in addressing the needs of the people you are working with.

In reflecting on how they (the student) had started to feel a deeper empathy for those they were working with, I advised the students that:

This deep sense of injustice and unfairness that you have developed can be seen infiltrating your practice. It is clear that is has shaped your practice in terms of how you engage with others but also your sense of injustice and the need to do something about it.

The influence of the social determinants of health on daily life became more visible as an issue that the occupational therapy profession needed to find ways of addressing. As professionals we need to acknowledge that those invisible factors affect the health and well-being of our clients.

\section{Category 2: Equals working for change}

Through recognising their common humanity and shared citizenship with clients, students realised that they had to think critically about how they engaged with clients. Students reflected on the significance of gaining a shared understanding with clients. The excerpt below shows one of my responses to this.

Developing a shared understanding (of your client's situation) where you share about yourself authentically, is an ongoing process and important in gaining trust and affecting change together.

The benefits of using a participatory approach were reflected in students' logs where they reported on appreciating a richer understanding of those factors that affected the possibilities of clients' engagement in occupations. This allowed students to collect richer data from their clients, enriching the rationale and design of their interventions. I noticed that:

Clients would share intimately about their lives, how they deal with poverty or violence and their worries about their loved ones. The students witnessed how this unfolded in clients' lives as they participated collectively in occupations. For example, students played with the children in the playground and like them, risked having to seek refuge in the nearest classroom if any shooting started, or at another placement, students would assist seniors with meal preparation, using ingredients sparingly to stretch for the week. They appreciated the way in which intersectionality shaped participation and started to question and use this, rather than using labels such as 'disabled people'. Students reflected on their assumptions about people and began to base their practices on their understandings generated while working in equal partnerships with people.

During supervision with students, I observed students feeling challenged in navigating an authentic partnership approach with clients. Developing authentic partnerships required that students not only relate to clients as professionals but to connect with them as people. In one example a student shared that she had been feeling ill but was afraid of being unprofessional if she informed the clients. The clients could sense that something was wrong, but the student was determined to remain professional and didn't know whether she could share how she was feeling. I responded:

Of course you should share! You are human before a professional and it is quite appropriate to share human things with other humans. The clients are your fellow citizens- they too have green ID books and they are South African just like you.

I was aware of the anxiety about making authentic connections where both professional and client value each other's thinking and experience. In developing relationships in this way, students and therapists needed to display some vulnerability in front of clients. I recalled this experience as a novice therapist. This involved, for example, becoming more comfortable with sharing more about oneself during an assessment process so that information was not simply extracted but rather shared. I reflected that:

In adopting this approach, students struggle to cross over that "professional boundary' and are still re-defining their personal boundaries. The students found it challenging to switch from a clinical understanding of their relationships to a relationship where power was shared more equally.

The students reported that practicing in partnership with clients along with a deeper appreciation of the practice context, changed them on a personal level. As an extension of the mutual trust and 
understanding in their relationships, their practice occurred in places that were familiar to people in the community instead of only in institutions. This meant that:

...students would work in local library halls, old vacant buildings, churches, people's garages and taxi ranks.

Decision -making related to the location of services occurred through ongoing communication with and negotiation between students and stakeholders. This required that both supervisor and students kept themselves informed of current happenings in the community. This involved listening to news on radio stations, reading local newspapers and creating WhatsApp groups with local community members and staff on site in order to remain connected to different activities and possible risks associated with working in these different places. Exchanging cell phone contact details with selected clients could be viewed as unprofessional but in this way of working, the intention was to promote accessible communication and the exchange of numbers was confined to matters related to service delivery. In this way communication was based on the reciprocal relationship and its boundaries, including mutual trust.

Many students became more conscious citizens in that they have gained a deeper insight into the lived realities that their future clients may be discharged back to. Some students returned to communities in their personal capacities to simply stay connected or follow through on promises or objectives of the campaign with the group of people that they were working with.

I realised that

Learning how to shift is a gradual process where students come to appreciate that without a reciprocal relationship they find it difficult to facilitate change. When students do engage authentically and develop an intimate trust with communities and understand their needs, it requires time. I had to find a balance of ensuring that the students still walked away with a skills set and a level of competency in a seven week period but that they also don't rush a developmental and authentic process. It was a challenge in balancing the benefit of slow process orientated with the academic requirements.

Similarly, managing time and academic requirements were often mentioned in student logs as students wrestled with allowing processes to unfold at their own pace within campaigns in order to bring about change. This required that the students work flexibly and allow the developmental pace of the community to lead processes of change. The comment offered by myself to the student was as follows:

You have added through planting a seed to the development of this community and client group and in doing this, you didn't have to find the ultimate solution but rather that you have contributed to a process of change.

I viewed practicing in community development as

A space where you learn how to engage with clients in a manner where reciprocity is valued.

Some students felt the burden of success or change rested on their shoulders as health professionals leading them to feel the expectation to perform and design a perfect solution. This went against the philosophy of community development practice where change rather than solutions are valued, as reflected by myself.

Development is valued rather than solutions. Students become anxious about not having enough time to see the impact of interventions. Not enough time, not enough solutions.

Given this perspective, I reminded another student about how development should be experienced.

You need to realise that development happens with or without you and that there are others out there that too are contributing to the development process.
I continued to reflect on what is required for a Development perspective:

I recognised that the academic requirements were non-negotiable and that I needed to make sure that students are given opportunities to apply methodologies in practice. I also recognised that the community was not always ready for a particular methodology or space. This required me to have an intimate understanding of the barriers and complexities in that particular community and evaluating students fairly against those. Being flexible, compromising, having numerous back-up plans and negotiating various obstacles is an important set of skills that students had come to develop. Letting students know that I understood if things didn't go according to plan and that this is the nature of working in domains that are dynamic and real.

The students came to recognise that people have the capacity to be agents of change and that being authentic with stakeholders gave students the permission to not perform as the distant professional and expert with all the solutions. A student expressed her awareness of not knowing what to do or say while being with clients and the pressure of not knowing the answers was evident throughout her reflections. I encouraged them by responding that

Sharing with people that you don't know the answer can also be good.

I also commented in supervision that

Being vulnerable in front of clients and openly saying that you don't know the solution nor have the answers is much needed to encourage people to address their own needs.

I realised that she too held the mind-set of being expected to have all the solutions and became overwhelmed with navigating the obstacles alone. In the excerpt below I reflect on her thinking while I was practicing in a clinical setting.

Can you imagine telling $D$ the quad that he can play wheelchair rugby and the closest club was in Mitchells Plain. How on earth was he going to get there? Where was he going to get the money to hire transport? Who was going to assist him with his coughing and tilting for when he became dizzy? How was he going to get out the path between his shack and the neighbour? Engaging in occupations seemed so far-fetched ... He just needs to stay alive and not get worse.

As a clinician at the time, I assumed the responsibility of asking and answering all the questions above instead of thinking of ways to collaborate with others. I also had to confront the language and labels that I had become accustomed to using when referring to clients. I realised that I too witnessed other professionals feeling the burden and pressure to find solutions alone and accept failure as a people-based problem instead of critically considering contextual factors. In the excerpt below I describe how projects/programmes - when planned without people - often fail because people often only get included in the implementation phase of projects and not in the initial planning.

I can't count how many times projects worth thousands have failed or faded because of this response. They (colleagues) would be visibly angry with the community for only 3 mothers pitching for sessions.

Upon further reflection, I recognised that partnering with clients from the start and not merely delivering a project for or on them as well as evaluating together with clients was essential to bringing about change. A student reflected on the anxiety she was experiencing in not having enough time to make a difference in the lives of the clients and I recalled experiencing a similar feeling, a pressure to be the only professional to solve it. In response to the student I commented:

You need to recognise that development and change is always happening and that you, as well as many other stakeholders are contributing to that change. You are not the only one trying to bring about change.

Partnering and collaborating with others is needed for long term sustainable change to happen. I commented that in practice once they were qualified they too would need to balance administrative 
and management demands and working developmentally in addressing needs of the patient. I recalled how:

In health facilities the time spent with patients is brief and intense, often only enough to train and provide home programme.

Collaboration is about building strategic relationships with stakeholders who can contribute to bringing about change.

\section{Theme: Towards socially responsive practice}

Progress towards socially transformative focus in practice was evident in the process of becoming alert to the influence of the social determinants of health on people's everyday lives (category one) and then drawing on this knowledge to enact a participatory, collaborative approach to practice (category two). Since using a collaborative approach was shaped by the demands of the context, it opened up possibilities to prioritise with clients what pressing needs needed to be addressed in clients' everyday lives, as the following quote alludes to.

Clients are discharged back into the very environments that have caused their disability. In these environments [that] clients live [in] with; where they will experience stigma, physical inaccessibility and struggle with the competing demands of securing food, income and shelter or adhering to the expectation [of therapists to meet therapeutic goals] often competes with rehabilitation outcomes. This may mean that clients may not utilise home programme/assistive devices at times due to the constraints of the environment.

Some students working in sites where occupational therapists were employed, experienced pressure from the therapists to perform traditional clinical services. I was familiar with these pressures as I too had experienced this as a therapist working in community development practice. I had faced many tensions, curiosity, probing questions and inquiry from colleagues into the need or validity of this domain of practice.

In South Africa occupational therapy is understood to be clinical and clearly positioned in either health or education. 'Community' is normally regarded to be territory of the Social Work profession. It was challenging to navigate the unknown territory but remain confident and passionate in the face of incredulous inquiry.

While occupational therapists traditionally have been concerned with medical diagnoses and their related outcomes, for example, cerebravascular accidents, addressing social conditions may be positioned as equally concerning. This would mean that for the person who has a diagnosis of cerebral-vascular accident, for example, but lives in poverty, addressing poverty too becomes a concern for the occupational therapist. Creating practices in occupational therapy that incorporates such shifts in focus is important since both must be considered equally problematic situations to occupational therapists.

Forming collaborative partnerships with clients where power was shared, differed from the therapeutic relationships usually developed when delivering clinical services. The form of professionalism applied in such therapeutic relationships did not require that therapists bring their intersectional identities into view for analysis. I reflected that insights into partnerships and contexts could assist in understanding occupational therapy services more broadly, as illustrated in this feedback offered:

Yes, a health system that is meant to help people can also be burdensome and appreciating the view from the others side is helpful as your current understanding of the health system is only from your side as the service provider. Having a different perspective and not being judgemental helps you to find the resources inside you to be what you need to be for the patients. It requires even more stretching from you.

Transitioning towards socially responsive practice provides a way of beginning to apply critical perspectives to practice and recognise that the focus could shift towards addressing the invisible factors impacting on participation and the occupational well-being of clients. I reflected on how professionals I had worked with struggled to critically evaluate those invisible factors that impact on participation. I recalled some of the comments that I faced from others, such as:

These people don't want change and

You can't make the horse drink and

They don't appreciate what we do for them.

The comments above came from professionals who held a narrow perspective of the changes that they wanted to see or even of the approaches that could be implemented. The findings suggest that not only the context and critical perspectives, but also the quality of relationships with clients, shapes the possibilities for socially responsive practice.

\section{DISCUSSION}

The findings of this study illustrate that occupational therapists could become more conscious of the way that macro-social processes affected their clients' everyday lives by learning from and with clients and their contexts. Creating spaces in practice in which to critically reflect on how the socio-political influences in patients' contexts shape their occupational engagement will foster a higher consciousness of these influences. Attention to the way that power contributes to occupational therapy processes with regards to the politics of human occupation, provides a lens through which the relationship between the way participation occurs in different contexts should be viewed ${ }^{8,12}$. The findings of this paper showed that an awareness of one's intersectional identity as a professional is key to such reflection. Coulehan ${ }^{13}$ suggests that health professionals should adopt a narrative-based professionalism which involves self-awareness of one's own beliefs, feelings and attitudes and to not suppress or rationalise them.

\section{The theme}

Towards socially responsive practice, showed that insights were generated through critical reflection and an awareness of relational power and thus moved "beyond the rigid limits of traditional approaches to health and social care to work toward equity, occupational justice..."14:176. Shifts towards participatory approaches in practice brought about opportunities to collaborate with clients in identifying actions that could promote change. This approach created the chance to action a decolonial approach where knowledge and social action could be co-constructed, such as in the application of participatory approaches (described in category two: Equals working for change), with recognition that these processes are subjective ${ }^{15}$. This subjectivity should not be mistaken for an individual's experience; rather, as shown in the findings, it refers to the way in which social positioning influences relationships and participation. Therapists themselves are to be considered as active agents in promoting social justice, with the findings supporting the epistemological assumption that unequal power relations maintain oppressive systems that exist ${ }^{16}$ and should be challenged through occupational therapy.

We further suggest that, as a starting point, health professionals should learn from and work with the challenges that contexts place on clients' participation. This allows for people working together to gain understanding of the problems and seek solutions together and for everyone's thinking, humanity and dignity to be respected and valued. If as health professionals, our primary concern is the health of individuals and communities, then poverty reduction, economic and social development should be included in our agenda ${ }^{17}$. Ways of promoting shifts in practice that facilitate changes in the social conditions that affect people's lives need to be developed. Scholars in occupational science have identified that the epistemological perspectives underlying such shifts require that macro social processes, political and economic factors ${ }^{17}$ shaping marginalised and oppressed people's everyday lives have to be taken into account to advance social transformation.

\section{Implications for practice}

Therapists need to be intentional about researching and remaining up to date with current happenings in communities from which 
their patients come by reading local newspapers, listening to local radio stations and learning from patients. In doing so, the patient becomes the expert of their community and power is shared more equally between therapist and patient. Furthermore, therapists should seek and create opportunities to become more directly familiar with communities where their clients reside in order to learn about the barriers to participation and the socio-political factors that contribute to occupational injustice. While therapeutic goals, especially in clinic settings may prevail, these should not only be designed with the patient but importantly, with full consideration of the socio-political contexts into which they are being discharged. Notwithstanding, this may place somewhat unfamiliar and unconventional expectations on therapists and clients regarding ethical reasoning as guided by the Health Professionals Council of South Africa and calls for critical reasoning so that both intentions and outcomes are considered in deciding on actions in a manner where therapists always prioritise their responsibilities towards their clients, and communities, continuously working for social change.

Lastly, therapists should intentionally and strategically foster relationships with a broad range of relevant stakeholders, (including the patient in the community also committed to addressing the social determinants of health) so as to move from an individualistic approach to rather an inclusive approach in bringing about change. All stakeholders are responsible for change with the goal of not just to develop an ultimate solution but rather to contribute to a process of change.

\section{Limitations}

The findings in this paper could have been enriched if students' reflections were included in the set of data. However, revealing my insights as both the clinical educator and therapist's reflections has yielded valuable insights. I intend on continuing with this research by engaging with more students and qualified occupational therapists.

\section{CONCLUSION}

The distribution and focus of occupational therapy services in South Africa may preclude occupational therapists from fully contributing to improving the health of all South Africans. To promote a socially transformative focus in practice, the profession needs to embrace a broader interpretation of engagement in occupations, taking into account the structural and socio-political factors that affect the health and participation of people in communities.

\section{REFERENCES}

I. Mayosi B., Benatar S. Health and health care in South Africa- 20 Years after Mandela. The New England Journal of Medicine. 2014; 37I: I344-I353.

2. Bradshaw D.: Determinants of health and their trends In: 2008 South African Health Review Issue I. South African Medical Research Council. 2008: 5I-69.

3. Coovadia H., Jewkes R., Barron P., Sanders D. and Mclntyre D: The health and health system of South Africa: historical roots of current public health challenges. Lancet. 2009; 374: 817-834.

4. Pillay R. A perspective on Occupational Therapy in Public Health Sector in South Africa: challenges, opportunities and achievements. Oral presentation presented at World Occupational Therapy Day Virtual exchange, October 2017.

5. Benatar $\mathrm{S}$. The challenges of health disparities in South Africa, South African Medicine Journal. 2013; I03(3): I54-I55.

6. Hammell K. R. W., Iwama, M. K. Well-being and occupational rights: An Imperative for critical occupational therapy. Scandinavian Journal of Occupational Therapy. 2012; 19: 385-394.

7. Galvaan R., Peters, L. Occupation-based community development framework. 2013. https://vula.uct.ac.za/access/content/ group/9c29ba04-b lee-49b9-8c85-9a468b556ce2/OBCDF/index. html (23 March 2017).

8. Galvaan R., Peters L. Occupation-based community development: Confronting the Politics of Occupation. In Pollard N., Sakelleriou D. (Eds.) Occupational Therapies without Borders: Integrating justice with practice (2nd edition). United Kingdom: Elsevier Limited; 2017.

9. Bullough R. V., Pinnegar S. Guidelines for quality in autobiographical self-study research. Educational Researcher. 200I; 30: I3 - 2 I.

10. Clandinin, D. J. and Connelly, F. M. Narrative inquiry: Experience and story in qualitative research. San Francisco: Jossey-Bass Publishers; 2000.

I I. Feldman A. Validity and Quality in Self Study. Educational Researcher, 2003; 32: 26 - 28.

12. Ramugondo E. Intergenerational Play within Family: The case for Occupational Consciousness. Journal of Occupational Science. 2015; 19(4): 326-340.

13. Coulehan J. Viewpoint: Today's Professionalism: Engaging the mind but not the heart. Academic Medicine. 2005; 80: 892 - 898.

14. Malfitano A., de Souza R. and Lopes R. Occupational Justice and its related concepts: A historical and thematic scoping review. OTJR: Occupation, participation and health. 2016; 36:4, 167-178.

15. Ndlovu-Gatsheni S. Global coloniality and the challenges of creating African futures. Strategic Review for Southern Africa. 2014; 36(2): |8|-202.

16. Farias L., Rudman D. and Magalhaes L. Illustrating the importance of critical epistemology to realise the promise of occupational justice. OTJR: Occupation, Participation and health. 2016; $36: 4,234-243$.

17. Boutayeb A. The double burden of communicable and non-communicable diseases in developing countries, Transactions of the Royal Society of Tropical Medicine and Hygiene. 2006; 100: 19I-199.

Corresponding Author

Leigh-Ann Richards

leighann.richards@uct.ac.za 